\title{
A Systematic Review and Meta-analysis of Retrospective Series of Regorafenib for Treatment of Metastatic Colorectal Cancer
}

\author{
JOEY MERCIER ${ }^{1}$ and IOANNIS A. VOUTSADAKIS ${ }^{1,2,3}$ \\ ${ }^{1}$ Northern Ontario School of Medicine, ${ }^{2}$ Division of Clinical Sciences, Sudbury, ON, Canada; \\ ${ }^{3}$ Algoma District Cancer Program, Sault Area Hospital, Sault Ste Marie, ON, Canada
}

\begin{abstract}
Background: Metastatic colorectal cancer is a common disease encountered in oncology practice and treatment options beyond fluoropyrimidines, irinotecan, oxaliplatin and monoclonal antibodies against epidermal growth factor receptor and vascular endothelium growth factor (VEGF) are limited. Regorafenib, a new drug that targets tyrosine kinases such as VEGF receptor as well as others, has been added recently to the armamentarium for metastatic colorectal cancer. This report analyzes the published experience with this drug in clinical practice outside of clinical trials. Materials and Methods: A literature search of major databases was performed for the identification of studies of regorafenib in metastatic colorectal cancer. Studies retained for further analysis were in English or French, describing 20 or more patients treated with regorafenib monotherapy and not part of a phase I, II or III trial. Results of the pooled analysis of retrospective studies were compared with results of the published phase III trials and a phase IIIb prospective study. Results: Twelve publications including a total of 702 patients were included in the meta-analysis. Summary response rate was 2\% [95\% confidence interval $(C I)=0.8-3.2 \%$ ] and the disease control rate $38.14 \%$ (95\% CI=32.35-43.93\%). Summary survival rates were 3.34 months (95\% CI=2.71-3.97 months) for progression-free and 7.27 months (95\% CI=6.23-8.3 months) for overall survival. These were similar to the phase III and
\end{abstract}

This article is freely accessible online.

Correspondence to: Ioannis A. Voutsadakis, MD, Ph.D., Algoma District Cancer Program, Sault Area Hospital, 750 Great Northern Road, Sault Ste Marie, ON P6B 0A8, Canada. E-mail: ivoutsadakis@yahoo.com, ivoutsadakis@nosm.ca

Key Words: Colorectal cancer, metastatic, regorafenib, VEGFR, inhibition, retrospective series.
IIIb studies. Most common adverse effects were also consistent with those of the published phase III experience. Conclusion: This systematic review and meta-analysis confirmed a moderate efficacy of regorafenib in later-stage metastatic colorectal cancer in the everyday clinical practice setting outside of clinical trials. Future identification of biomarkers may aid in further tailoring of this treatment in order to obtain maximum clinical benefit.

Colorectal cancer is the most common gastrointestinal malignancy in the Western world and remains a prominent cause of cancer morbidity and mortality, despite progress in its management. It affects approximately 746,000 men and 614,000 women yearly and it is the 3 rd most common cancer in the former and the 2nd most common in the latter (1). About one fourth of newly-diagnosed colorectal cancers are already in a metastatic stage and of those that are diagnosed in a localized stage nearly $50 \%$ will go on to develop metastatic disease, in most cases becoming unresectable. Metastatic colorectal cancer treatment options have been broadened to include regimens of oxaliplatin or irinotecan added to a fluoropyrimidine backbone, as well as targeted treatments with bevacizumab and, for $K R A S$ wild-type tumors, cetuximab or panitumumab (2-4). These treatments have extended the median survival of patients with metastatic colorectal cancer to over 2 years. Nevertheless, the disease remains incurable in most patients and when the above drug options have been exhausted, there is a paucity of other options. This therapeutic vacuum has been partially filled recently with the approval of the tyrosine kinase inhibitor regorafenib, a fluorinated derivative of sorafenib, for the third line treatment of metastatic colorectal cancer patients (5).

Regorafenib (formerly known as BAY 73-4506; chemical formula: $\mathrm{C}_{21} \mathrm{H}_{17} \mathrm{CIF}_{4} \mathrm{~N}_{4} \mathrm{O}_{4}$ ) is a small molecule multi-kinase inhibitor of fms-related tyrosine kinase 1 (FLT1, also known as vascular endothelial growth factor receptor 1, VEGFR1), 
kinase insert domain receptor (KDR, also known as VEGFR2), FLT4 (VEGFR3), TEK receptor tyrosine kinase, KIT proto-oncogene receptor tyrosine kinase, Raf-1 protooncogene, serine/threonine kinase, $\mathrm{v}$-RAF murine sarcoma viral oncogene homolog $\mathrm{B}$ (BRAF) and the commonly mutated $B R A F^{\mathrm{V} 600 \mathrm{E}}$ variant, platelet-derived growth factor receptor (PDGFR) and fibroblast growth factor receptor (FGFR) (6). It is orally available given at a dose of $160 \mathrm{mg}$ daily in an intermittent schedule of 3 weeks out of 4 . Regorafenib was approved in 2012 by the Food and Drug Administration as monotherapy for the treatment of metastatic colorectal cancer refractory to fluoropyrimidine, oxaliplatin and irinotecan-based chemotherapy, anti-VEGF therapy, and, if $K R A S$ wild-type, anti-epidermal growth factor receptor (EGFR) therapy (7). The approval was based on its efficacy compared to best supportive care in a phase III study that showed prolongation of progression-free survival (PFS) by 0.2 months and prolongation of overall survival (OS) by 1.4 months (8). An additional phase III trial confirmed these results, showing improvement of PFS by 1.5 months and of OS by 2.5 months (9). Moreover, a prospective series analyzing patients participating in a compassionate program showed a median PFS of 2.7 months and median OS of 5.6 months (10). Several small series have now been published describing the experience of individual centers or national programs with the drug in every day practice, all of which are off study. This current report sought to pool these studies and analyze the efficacy and toxicity of regorafenib in daily practice, outside of clinical trials and to compare the efficacy and toxicity observed in this setting with the trial experience.

\section{Materials and Methods}

Medline/PubMed and Embase databases were searched in order to identify published articles on regorafenib treatment for metastatic colorectal cancer. A search of the grey literature, in accordance with Cochrane's MECIR standards, was also performed to locate any unpublished studies on regorafenib (11). The search used the terms "regorafenib" and "metastatic colorectal cancer". Inclusion criteria were publication in English or French language, describing clinical experience in series of 20 or more patients evaluable for efficacy or toxicity, not being part of a phase I, II or III trial, and receiving regorafenib as a monotherapy. Publications in other languages or available only in abstract form were excluded. Also excluded were case reports or small case series (fewer than 20 patients), preclinical studies or reviews, and opinions and reports describing the experience of regorafenib in combination with other anti-neoplastic medications. A manual review of the references of retrieved articles was performed to locate additional relevant publications. To ensure the validity and reliability of the retrospective studies included in this paper, the risk of bias within each study was assessed using the ROBINS-I tool (12).

Data describing demographics of the patient population treated as well as efficacy and toxicity of regorafenib treatment were extracted from the included studies by one author and then reviewed by a second author to ensure accuracy. Discrepancies were discussed and reconciled cooperatively. Demographic characteristics of the patients treated with regorafenib recorded for the current pooled analysis consisted of the age of the patients, Eastern Cooperative Oncology Group performance status (ECOG PS), number and type of previous lines of treatment for metastatic disease, number and site of organs involved by metastatic cancer, location of the primary site (colon or rectum) and mutation status of KRAS. Response rate (RR), defined as the sum of complete (CR) and partial (PR) responses, disease control rate (DCR), defined as the sum of RR and stable disease (SD), median PFS and median OS were efficacy outcomes of interest and were extracted from the included publications. Toxicity of all grades, as well as grade 3 and 4 , were also outcomes of interest for this pooled analysis and where thus recorded from the published articles when available. A comparison was made with the respective pooled data of the regorafenib arms from the two published randomized phase III studies of the drug in metastatic colorectal cancer $(8,9)$ to determine whether the populations treated in phase III trials were similar to those reported off trial and whether the drug had a similar efficacy and toxicity profile when used in a trial setting to that in everyday practice. An additional comparison was made with the population and outcomes of a published prospective registry of regorafenib treatment (10).

Descriptive statistics were computed for both the characteristics of interest and the outcome measures. Some studies included in the pooled analysis did not provide complete population data, and, in those instances, the means and confidence intervals (CIs) were calculated using only the number of patients from the studies that included the data of interest. The number of series from which each outcome of interest was derived was determined and presented on each occasion. Heterogeneity amongst studies was evaluated with Cochran's $\mathrm{Q}$ and $\mathrm{I}^{2}$ tests. The fixed-effect model was used when between-study heterogeneity was low. Alternatively, when heterogeneity was moderate or high, a random-effect model was used for calculation of the pooled summary statistic (13). Calculations were performed in Excel (Microsoft Corp., Redmond, WA, USA) based on a previously described method with modifications as needed (14).

\section{Results}

Two hundred and thirty-eight publications were initially retrieved (Figure 1). Thirty-three studies were preclinical and were excluded. An additional 27 studies were excluded because they were not in English (none would have been included even if in English based on the abstract). From the remaining 178 clinical reports, 14 described regorafenib combined with other treatments, or its use in the treatment of other non-colorectal cancer types and were excluded. One hundred and twenty-eight articles were excluded either because they were reviews, opinions or editorials, or addressed special topics. Thirty-two retrieved articles were clinical trials or series. After exclusion of 12 reports describing phase I, II and III trials and eight case reports or series with few patients, 12 retrospective series remained to be included in the current analysis (15-26). These reports were published between 2015 and 2017 and described a total of 702 patients (Table I). 


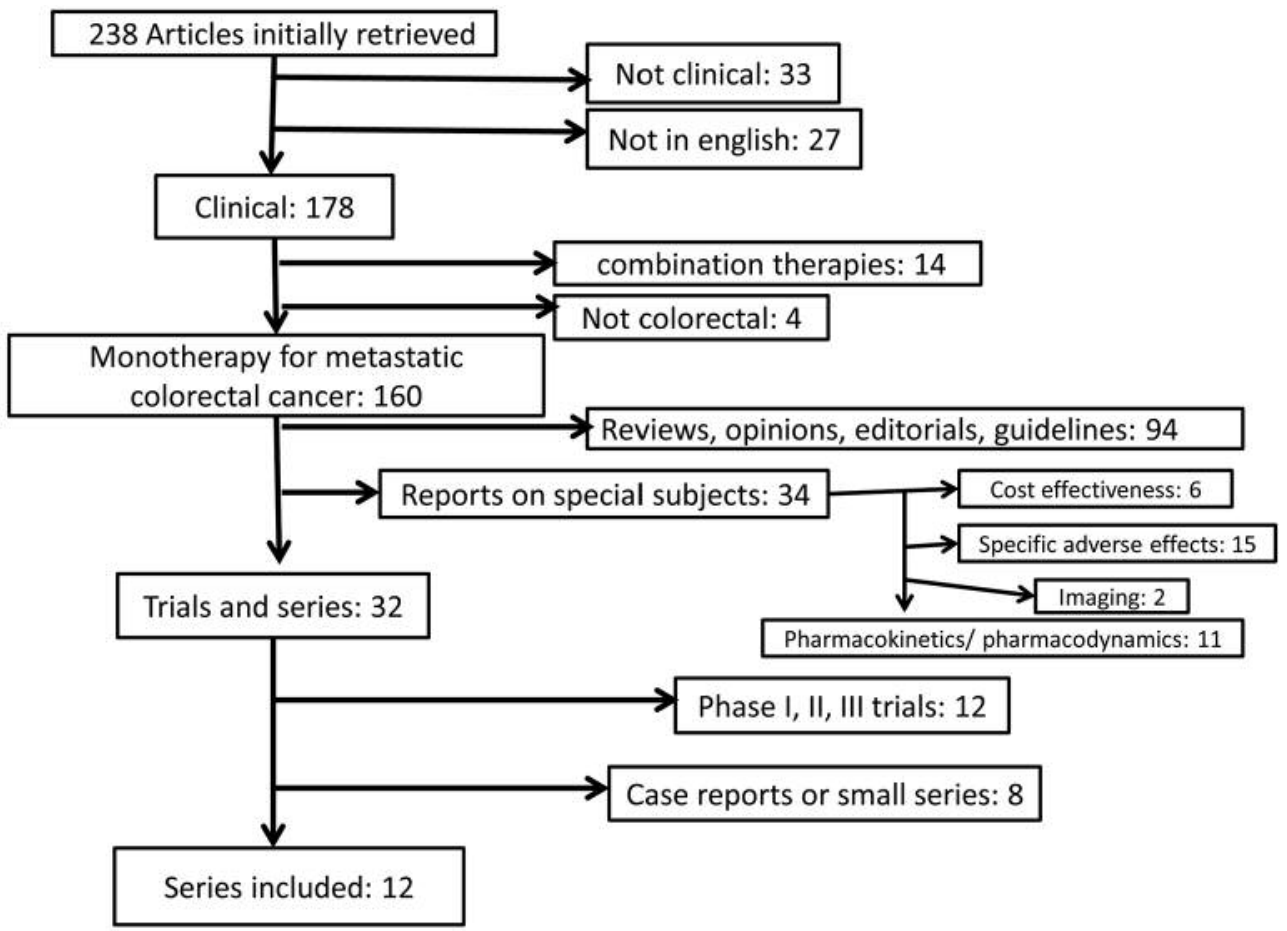

Figure 1. Number of studies retrieved and evaluated for this analysis and reasons for exclusion.

Table I. The 12 studies included in this pooled analysis of regorafenib in patients with metastatic colorectal cancer, the CORRECT (8) and CONCUR (9) phase III trials, and the REBECCA observational cohort study (10).

\begin{tabular}{|c|c|c|c|c|c|c|}
\hline Study (Reference) & $\begin{array}{c}\text { Year of } \\
\text { publication }\end{array}$ & Country & $\begin{array}{c}\text { Number of } \\
\text { patients }\end{array}$ & $\begin{array}{c}\text { Number of evaluable } \\
\text { patients }\end{array}$ & $\mathrm{RR}(\%)$ & $\operatorname{CBR}(\%)$ \\
\hline Osawa (15) & 2017 & Japan & 20 & 17 & 5.9 & 58.8 \\
\hline Lam et al. (16) & 2016 & Hong Kong & 45 & 31 & 3.2 & 35.5 \\
\hline Masuishi et al. (17) & 2016 & Japan & 146 & 134 & 0.8 & 32.8 \\
\hline Calcagno et al. (18) & 2016 & France & 29 & 27 & 0 & 25.9 \\
\hline Zanwar et al. (19) & 2016 & India & 23 & 23 & 8.7 & 43.5 \\
\hline Kim et al. (20) & 2015 & South Korea & 32 & 29 & 3.4 & 55.1 \\
\hline Hirano et al. (21) & 2015 & Japan & 32 & 28 & 0 & 39.3 \\
\hline Giampieri et al. (22) & 2017 & Italy & 144 & 132 & 6.8 & 34.8 \\
\hline Lim et al. (23) & 2017 & South Korea & 40 & 40 & 7.5 & 65.0 \\
\hline Kakizawa et al. (24) & 2017 & Japan & 20 & 13 & 0 & 23.1 \\
\hline Kopeckova et al. (25) & 2017 & Czech Republic & 148 & 121 & 3.3 & 45.5 \\
\hline Sueda et al. (26) & 2016 & Japan & 23 & 23 & 0 & 30.4 \\
\hline Adenis et al. (10) & 2016 & France & 654 & 654 & NR & NR \\
\hline Grothey et al. (8) & 2013 & Multiple (International) & 505 & 500 & 1.0 & 41.0 \\
\hline Li et al. (9) & 2015 & Multiple (Asia) & 136 & 136 & 4.0 & 51.0 \\
\hline
\end{tabular}

NR: Not reported.

Most series (nine out of 12) were from Asia (five from different centers in Japan, two from South Korea and one each from Hong-Kong and India). Three studies were from Europe (Table I). Most patients included in the 12 series had a good performance status (ECOG PS 0 or 1) and only about $7 \%$ had a PS of 2 (Table II). Slightly more than half of the patients $(56.8 \%)$ had a colon primary tumor and $43.2 \%$ had a rectal primary tumor. The most common sites of metastatic 
Table II. Patient characteristics and efficacy in patients from the CORRECT (8) and CONCUR (9) phase III trials, the REBECCA observational cohort study (10), and the current pooled analysis of retrospective studies. In the p-value column, the first number of each comparison refers to comparison of the pooled retrospective studies with phase III studies and the second number to comparison of the pooled retrospective studies with the REBECCA study, when available.

\begin{tabular}{|c|c|c|c|c|c|}
\hline & $\begin{array}{l}\text { Phase III studies } \\
\qquad(\mathrm{n}=641)\end{array}$ & $\begin{array}{c}\text { REBECCA } \\
(\mathrm{n}=654)\end{array}$ & $\begin{array}{c}\text { Pooled retrospective } \\
\text { studies }\end{array}$ & $\begin{array}{c}\text { Total patients with } \\
\text { data/series with data, } \mathrm{n}\end{array}$ & $\underset{p \text {-Value }}{\chi^{2}}$ \\
\hline $\begin{array}{l}\text { Median age, years } \\
57.5(\mathrm{IQR}=50-66)\end{array}$ & $61(\mathrm{IQR}=54-67)$ & $64($ range $=25-91)$ & $56(\text { range }=22-85)^{*}$ & $702 / 12$ & \\
\hline ECOG PS & & & & $702 / 12$ & \\
\hline Median & $1(\mathrm{IQR}=0-1)$ & $1($ range $=0-3)$ & $1($ range $=0-2)$ & & \\
\hline 0 & $300(46.8 \%)$ & $200(30.6 \%)$ & $219(51.3 \%)$ & $459 / 8$ & \\
\hline 1 & $341(53.2 \%)$ & $383(58.6 \%)$ & $171(40.0 \%)$ & $315 / 7$ & \\
\hline 2 & 0 & $60(9.2 \%)$ & $37(8.7 \%)$ & $495 / 9$ & \\
\hline 3 & 0 & $9(1.4 \%)$ & 0 & $702 / 12$ & \\
\hline \multicolumn{6}{|l|}{ Primary site, $\mathrm{n}(\%)$} \\
\hline Colon & $402(62.7 \%)$ & $445(68.0 \%)$ & $186(56.9 \%)$ & $327 / 8$ & 0.004 \\
\hline Rectum & $204(31.8 \%)$ & $186(28.4 \%)$ & $141(43.2 \%)$ & $327 / 8$ & 0.00001 \\
\hline Both & $34(5.3 \%)$ & $5(0.8 \%)$ & & & \\
\hline Unknown & $1(0.2 \%)$ & $18(2.8 \%)$ & & & \\
\hline \multicolumn{6}{|c|}{ Prior lines of chemotherapy, n (\%) } \\
\hline $1-2$ & $183(28.5 \%)$ & NR & $209(50.6 \%)$ & $413 / 6$ & $<0.00001$ \\
\hline 3 & $157(24.5 \%)$ & NR & $148(35.8 \%)$ & $413 / 6$ & \\
\hline$\geq 4$ & $297(46.3 \%)$ & $98(15.0 \%)$ & $56(13.6 \%)$ & $413 / 6$ & \\
\hline Median & & & $2-4$ & $556 / 11$ & \\
\hline Range & & & $1->4$ & & \\
\hline \multicolumn{6}{|l|}{ No. of organs involved } \\
\hline Single & $28(20.6 \%)$ & $203(31.0 \%)$ & $18(7.0 \%)$ & $85 / 2$ & \\
\hline Multiple & $108(79.4 \%)$ & $314(48.0 \%)$ & $239(93.0 \%)$ & $379 / 4$ & \\
\hline \multicolumn{6}{|l|}{$K R A S$ status } \\
\hline Wild-type & $255(39.8 \%)$ & $291(44.5 \%)$ & $324(51.6 \%)$ & $662 / 11$ & 0.01 \\
\hline mutant & $319(49.8 \%)$ & $331(50.6 \%)$ & $304(48.4 \%)$ & $662 / 11$ & 0.089 \\
\hline \multicolumn{6}{|l|}{ Sites involved } \\
\hline Lung & NR & NR & $141(64.7 \%)$ & $218 / 4$ & \\
\hline Liver & NR & NR & $158(43.2 \%)$ & $366 / 5$ & \\
\hline Peritoneum & NR & NR & $50(22.9 \%)$ & $218 / 4$ & \\
\hline Lymph nodes & NR & NR & $96(48.5 \%)$ & $198 / 3$ & \\
\hline Bone & NR & NR & $3(21.2 \%)$ & $23 / 1$ & \\
\hline \multicolumn{6}{|c|}{ Types of prior chemotherapy } \\
\hline Fluoropyrimidines & NR & NR & $454(100.0 \%)$ & $454 / 8$ & \\
\hline Irinotecan & NR & $647(99.0 \%)$ & $452(99.6 \%)$ & $454 / 8$ & \\
\hline Oxaliplatin & NR & $647(99.0 \%)$ & $445(98.0 \%)$ & $454 / 8$ & \\
\hline Bevacizumab & $561(87.5 \%)$ & $602(92.0 \%)$ & $567(91.9 \%)$ & $617 / 10$ & \\
\hline Anti-EGFR & $48(7.5 \%)$ & $283(43.3 \%)$ & $298(48.3 \%)$ & $617 / 10$ & \\
\hline \multicolumn{6}{|l|}{ Efficacy } \\
\hline $\begin{array}{l}\text { Median OS }(95 \% \mathrm{CI}) \text {, } \\
\text { months }\end{array}$ & $\begin{array}{c}6.4(\mathrm{IQR}=3.6-11.8) \\
8.8(7.3-9.8)\end{array}$ & $5.60(\mathrm{IQR}=2.4-11.4)$ & $7.27(6.23-8.3)$ & $566 / 10$ & \\
\hline $\begin{array}{l}\text { Median PFS }(95 \% \mathrm{CI}) \text {, } \\
\text { months }\end{array}$ & $\begin{array}{c}1.9(\mathrm{IQR}=1.6-1.9) \\
3.2(2.0-3.7)\end{array}$ & $2.70(\mathrm{IQR}=1.6-4.6)$ & $3.34(2.71-3.97)$ & $568 / 10$ & \\
\hline $\mathrm{RR} \%(95 \% \mathrm{CI})$ & $\begin{array}{l}1.0(0.1-1.8) \\
4.4(1.0-7.9)\end{array}$ & NR & $1.99(0.78-3.19)$ & $618 / 12$ & \\
\hline DCR $\%(95 \% \mathrm{CI})$ & $\begin{array}{l}41.0(36.7-45.3) \\
51.5(43.1-59.9)\end{array}$ & NR & $38.14(32.35-43.93)$ & $618 / 12$ & \\
\hline
\end{tabular}

ECOG PS: Eastern Co-operative Oncology Group performance status, EGFR: epidermal growth factor receptor, OS: overall survival, PFS: progression free-survival, RR: response rate, DCR: disease control rate, NR: not reported, IQR: interquartile range; §Where two values are given, the first refers to the CORRECT study and the second to CONCUR. *Median of medians.

involvement were the lungs, lymph nodes and liver, while more than a fifth of the patients had metastatic disease to bones and peritoneal seeding. About two-thirds of patients had multiple organ involvement. The median number of prior lines of chemotherapy ranged from 2 to 4 in the series. About half the included patients for whom data were 


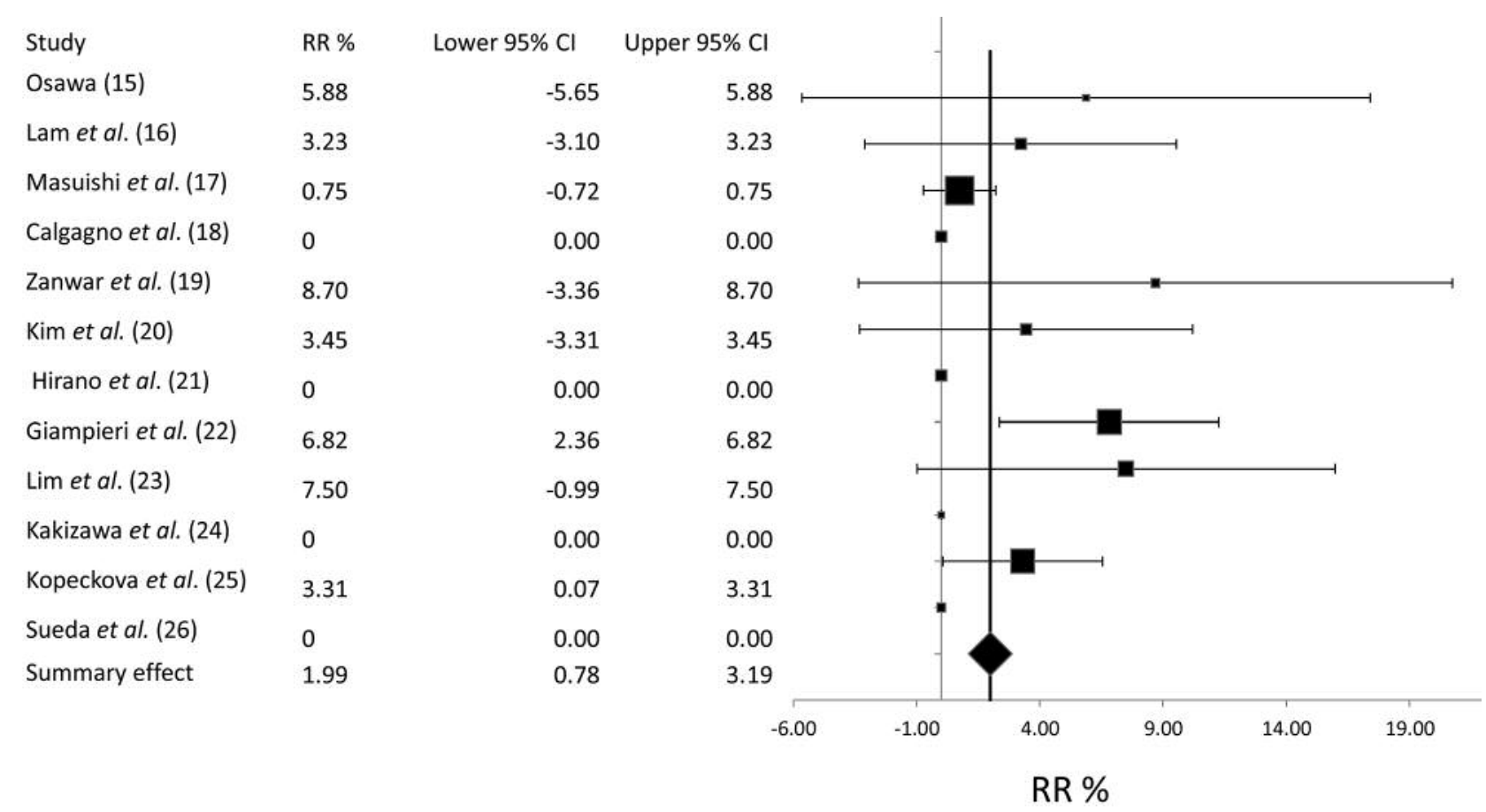

Figure 2. Pooled analysis of response rates (RR). CI: Confidence interval.

provided had had one or two previous lines of chemotherapy for metastatic disease, while the other half had three previous chemotherapy lines (35.8\% of patients) or four and more lines (13.6\%). All patients for whom information was provided had previously received 5-fluoropyrimidines and almost every patient had also received oxaliplatin and irinotecan (Table II). About $92 \%$ of patients had also been exposed to bevacizumab and about half of the patients had also received a monoclonal antibody to EGFR. This was equal to the percentage of patients that had disease with wild-type $K R A S$.

A pooled analysis of $\mathrm{RR}$ to regorafenib monotherapy treatment was based on all 12 analyzed studies and included a total of 618 evaluable patients. The pooled RR was quite low at $2 \%(95 \% \mathrm{CI}=0.8-3.2 \%)$ (Figure 2). Three studies included no responding patients and in most studies the $95 \%$ CI crossed zero. Heterogeneity between studies was low and the $I^{2}$ value was 4.3 (Cochran's $\mathrm{Q}=11.49, \chi^{2} p=0.4$ ). Thus, calculations were made under a fixed-effect model.

The DCR analysis was also based on all 12 studies (618 evaluable patients) and disclosed a pooled DCR of $38.14 \%$ (95\% CI=32.35-43.93\%) (Figure 3). Between-study heterogeneity was low to moderate $\left(I^{2}=19\right.$, Cochran's $\mathrm{Q}=13.6$, $\left.\chi^{2} p=0.25\right)$ and thus a random-effect model was preferred.

Ten studies totaling 568 evaluable patients had available data on PFS. Heterogeneity was high $\left(I^{2}=81\right.$, Cochran's
$\left.\mathrm{Q}=48.5, \chi^{2} p<0.00001\right)$ and thus a random-effect model was applied. The pooled PFS was 3.34 months $(95 \% \mathrm{CI}=2.71-$ 3.97 months) (Figure 4).

OS data were available from 10 studies with a total of 566 evaluable patients. Nine out of the 10 studies were the same as those included in the PFS analysis and one study (18) had only OS information, while another study (20) provided PFS but not OS information. Between-study heterogeneity in the case of OS evaluation was moderate $\left(I^{2}=36\right.$, Cochran's $\left.\mathrm{Q}=14.2, \chi^{2} p=0.11\right)$ and a random-effect model was used. The pooled OS was 7.27 months (95\% CI=6.23-8.3 months) (Figure 5).

Median age of patients was similar in the randomized trials and the pooled retrospective series (Table I). Compared with phase III trials, which allowed only for patients with ECOG PS of 0 or 1 to participate as per their inclusion criteria, retrospective series had included a few patients $(8.7 \%)$ with ECOG PS of 2. On the other hand, patients in the phase III trials were more heavily pre-treated, with $46 \%$ having received four or more previous lines of treatment versus $13 \%$ in the retrospective series. Overall RR and DCR were similar in the pooled analysis of the patients in the retrospective series and the most extensive phase III trial (RR $1.99 \%$ and 1\%, respectively, and DCR $38 \%$ and $41 \%$, respectively) The other randomized phase III trial showed somewhat better RR and DCR in the regorafenib arm $(4 \%$ 




Figure 3. Pooled analysis of disease control rates (DCR). CI: Confidence interval.

and $51 \%$ ) but the CIs still overlapped (Table I). Survival outcomes were also similar, ranging between about 2 to 3.4 months for PFS and 6 to 8 months for OS.

As shown in Table III, several adverse effects of all grades were encountered in more than $10 \%$ of patients for whom data were available in the pooled series. Most common adverse effects encountered in more than two-fifths of patients included the hand and foot skin reaction (54.3\%), fatigue (50.2\%), anemia (45.4\%), thrombocytopenia (42.6\%), diarrhea (41.1\%) and anorexia (40.6\%) (Table III). Grade 3 and 4 adverse effects observed in more than $5 \%$ of patients for whom data were available in the pooled series included hand and foot skin reaction $(19.2 \%)$, hypertension $(7.3 \%)$, hyperbilirubinemia (6.2\%), rash/desquamation $(6.0 \%)$, thrombocytopenia $(5.3 \%)$ and anemia (5.1\%) (Table III). Grade 3 and 4 adverse effects in the phase III trials were similar, with the only additional grade 3 and 4 toxicities seen in more than $5 \%$ of patients being fatigue (8.2\%) and diarrhea (5.8\%).

\section{Discussion}

Regorafenib is a fluorinated aryl-urea derivative of the small tyrosine kinase inhibitor sorafenib, which was one of the first kinase inhibitors introduced in clinical practice in oncology in the treatment of renal cell carcinoma (27). Regorafenib has been studied and gained regulatory approval for use in gastrointestinal cancer, with colorectal cancer being its first approved indication in 2012 and later gastrointestinal stromal tumors and hepatocellular carcinoma $(28,29)$. Two prospective randomized trials showed small but possibly clinically meaningful benefits of regorafenib in pretreated patients with metastatic colorectal carcinoma. Median PFS intervals were 1.9 and 3.2 months in the regorafenib arms in these phase III trials, and gains compared to control were only 0.2 and 1.5 months respectively $(8,9)$. Median OS for regorafenib arms was 6.4 and 8.8 months in the two studies and gains were 1.4 and 2.5 months, respectively. Two other prospective open label studies, one of which has so far been published only in abstract form (30), have confirmed short PFS of 2.7 months in these mostly heavily pretreated patients with limited therapeutic options $(10,30)$. Median OS in the fully published study, which provided this information, was 5.6 months (10). Nevertheless, the clinical importance of even these small benefits of the drug has been debated by some authors and regorafenib is not without adverse effects (31). Moreover, it is unknown whether moderate benefits observed in the trial setting could be similarly obtainable in everyday clinical practice. This analysis sought to answer this question by pooling together results from several retrospective series in various countries. Both the pooled 




Figure 4. Pooled analysis of progression-free survival (PFS). CI: Confidence interval.



Figure 5. Pooled analysis of overall survival (OS). CI: Confidence interval.

PFS and OS estimate of these retrospective series (3.34 months, 95\% CI=2.71-3.97 months and 7.27 months, 95\% $\mathrm{CI}=6.23-8.3$ months, respectively) was found to be in the range of those observed in the trial setting. Similarly, RR was less than $5 \%$ in both phase III trials and our pooled analysis.
Regarding adverse effects of regorafenib in the retrospective series, they were in general consistent with those reported in the phase III trials, although all-grade hematological toxicities were higher. Grade 3 and 4 hematological adverse effects were also more often observed in the retrospective series but remained of low frequency at around $5 \%$ or less. 
Table III. Toxicity of regorafenib in patients from the CORRECT (8) and CONCUR (9) phase III trials, the REBECCA observational cohort study (10), and the pooled analysis of retrospective studies. Two retrospective studies report grade 2-4 toxicities only.

\begin{tabular}{|c|c|c|c|c|c|c|}
\hline \multirow[t]{2}{*}{ Toxicity } & \multirow{2}{*}{$\begin{array}{l}\text { Phase III studies } \\
(\mathrm{n}=636), \mathrm{n}(\%)\end{array}$} & \multirow{2}{*}{$\begin{array}{c}\text { REBECCA } \\
(\mathrm{n}=654), \mathrm{n}(\%)\end{array}$} & \multirow{2}{*}{$\begin{array}{l}\text { Pooled retrospective } \\
\text { studies, n (\%) }\end{array}$} & \multirow{2}{*}{$\begin{array}{l}\text { Total patients with data/ } \\
\text { series with data,n }\end{array}$} & \multicolumn{2}{|c|}{$\chi^{2} p$-value $v s$. pooled data } \\
\hline & & & & & Phase III & REBECCA \\
\hline \multicolumn{7}{|l|}{ All grades $(\%)$} \\
\hline HFSR & $333(52.4 \%)$ & $189(28.9 \%)$ & $279(54.3 \%)$ & $514 / 10$ & 0.52 & $<0.00001$ \\
\hline Diarrhea & $193(30.3 \%)$ & $123(18.8 \%)$ & $211(41.1 \%)$ & $514 / 10$ & 0.0002 & $<0.00001$ \\
\hline HTN & $170(26.7 \%)$ & $72(11.0 \%)$ & $103(28.0 \%)$ & $336 / 8$ & 0.20 & $<0.00001$ \\
\hline Rash/desquamation & $146(23.0 \%)$ & $26(4.0 \%)$ & $113(22.9 \%)$ & $494 / 9$ & 0.97 & $<0.00001$ \\
\hline Nausea/vomiting & $110(17.3 \%)$ & NR & $53(16.8 \%)$ & $315 / 7$ & 0.86 & \\
\hline Anorexia & $162(25.5 \%)$ & $96(14.7 \%)$ & $141(40.6 \%)$ & $347 / 8$ & $<0.00001$ & $<0.00001$ \\
\hline Oral mucositis/stomatitis & $138(21.7 \%)$ & $72(11.0 \%)$ & $86(23.2 \%)$ & $370 / 9$ & 0.57 & $<0.00001$ \\
\hline Fatigue & $260(40.9 \%)$ & $271(41.4 \%)$ & $258(50.2 \%)$ & $514 / 10$ & 0.0016 & 0.0028 \\
\hline Thrombocytopenia & $76(11.9 \%)$ & $21(3.2 \%)$ & $144(42.6 \%)$ & $338 / 8$ & $<0.00001$ & $<0.00001$ \\
\hline Leukocytopenia & $11(1.7 \%)$ & NR & $50(18.2 \%)$ & $275 / 5$ & $<0.00001$ & \\
\hline Neutropenia & $7(1.1 \%)$ & NR & $47(13.9 \%)$ & $338 / 8$ & $<0.00001$ & \\
\hline Anemia & $38(6.0 \%)$ & NR & $168(45.4 \%)$ & $370 / 9$ & $<0.00001$ & \\
\hline Hyperbilirubinemia & $95(14.9 \%)$ & $7(1.1 \%)$ & $140(39.7 \%)$ & $353 / 8$ & $<0.00001$ & $<0.00001$ \\
\hline \multicolumn{7}{|l|}{ Grade 3-4 (\%) } \\
\hline HFSR/skin & $105(16.5 \%)$ & $59(9.0 \%)$ & $71(19.2 \%)$ & $370 / 9$ & 0.28 & $<0.00001$ \\
\hline Diarrhea & $37(5.8 \%)$ & $28(4.3 \%)$ & $7(1.9 \%)$ & $370 / 9$ & 0.0033 & 0.043 \\
\hline HTN & $51(8.0 \%)$ & $30(4.6 \%)$ & $14(7.3 \%)$ & $192 / 7$ & 0.74 & 0.14 \\
\hline Rash/desquamation & $36(5.7 \%)$ & $8(1.2 \%)$ & $21(6.0 \%)$ & $350 / 8$ & 0.83 & $<0.00001$ \\
\hline Nausea/vomiting & $5(0.8 \%)$ & NR & $1(0.3 \%)$ & $315 / 7$ & 0.39 & \\
\hline Anorexia & $17(2.7 \%)$ & $19(2.9 \%)$ & $12(3.5 \%)$ & $347 / 8$ & 0.49 & 0.63 \\
\hline Oral mucositis/stomatitis & $16(2.5 \%)$ & $8(1.2 \%)$ & $5(1.4 \%)$ & $370 / 9$ & 0.22 & 0.86 \\
\hline Fatigue & $52(8.2 \%)$ & $95(14.5 \%)$ & $18(4.9 \%)$ & $370 / 9$ & 0.047 & $<0.00001$ \\
\hline Thrombocytopenia & $18(2.8 \%)$ & $1(0.2 \%)$ & $18(5.3 \%)$ & $338 / 8$ & 0.049 & $<0.00001$ \\
\hline Leukocytopenia & $3(0.5 \%)$ & NR & $4(1.5 \%)$ & $275 / 5$ & 0.12 & \\
\hline Neutropenia & $3(0.5 \%)$ & NR & $7(2.1 \%)$ & $337 / 8$ & 0.018 & \\
\hline Anemia & $16(2.5 \%)$ & NR & $19(5.1 \%)$ & $370 / 9$ & 0.029 & \\
\hline Hyperbilirubinemia & $19(3.0 \%)$ & 0 & $19(6.2 \%)$ & $309 / 7$ & 0.020 & $<0.00001$ \\
\hline $\begin{array}{l}\text { Treatment discontinuation } \\
\text { due to toxicity }\end{array}$ & NR & NR & $59(13.4 \%)$ & $441 / 8$ & & \\
\hline
\end{tabular}

HFSR: Hand and foot skin reaction, HTN: hypertension, NR: not reported.

There are some limitations to this analysis. Not every publication included in the analysis provided information for all outcomes of interest, thus pooled calculations for several of these outcomes had to rely on fewer patients. In addition, grouping of patients regarding baseline characteristics such as PS or previous lines of treatment was inconsistent between studies, and thus some studies had to be excluded from the pooled analysis. Completeness of reporting was also heterogeneous in different reports. The preponderance of reports came from Asian populations, thus making the relevance of results for other populations debatable. Nevertheless, two out of the three most extensive series $(22,25)$ accounting for more than half of the total patients analyzed were from Europe.

This meta-analysis of retrospective series of regorafenib in later lines of treatment of metastatic colorectal cancer is consistent with the results of prospective studies of the drug and confirms its modest usefulness as an option in this patient population, with a DCR of about $40 \%$ and no new adverse effects concerns. The challenge for further exploitation of the potential of regorafenib would be to identify markers of response in order to select subpopulations with particular sensitivity that would benefit most from treatment. This would allow other patients, who are less likely to respond, to avoid the adverse effects of the drug. In this respect, an exceptional response to regorafenib was reported in a patient with metastatic colorectal cancer and a mutation in the KDR gene encoding for VEGFR2 (32). This patient had an ongoing PR for over 9 months at the time of the report, despite being able to tolerate only a reduced dose of $40 \mathrm{mg}$. Another prolonged PR of 15 months as well as SD for over 20 months were observed in two patients participating in a phase I trial of the combination of regorafenib with cetuximab (33). Disease in both patients had previously progressed on each drug alone. The first 
patient was found to have a mutation in TP53 and the second was a patients with Lynch syndrome with an hypermutated tumor, harboring 99 mutations/megabase. Similar molecular analyses will undoubtedly provide a specific molecular profile of response to regorafenib and other drugs in order to guide optimal therapy in a personalized manner.

\section{Acknowledgements}

The Authors declare no conflicts of interest related to this study. No funding by any source has been received for the performance of this study.

\section{References}

1 Globocan. Globocan 2012: Estimated Cancer Incidence, Mortality and Prevalence Worldwide in 2012 - Fact Sheets by Cancer. 2012. http://globocan.iarc.fr/Pages/fact_sheets_cancer.aspx (accessed Jul 15, 2017).

2 Kirstein MM, Lange A, Prenzler A, Manns MP, Kubicka S and Vogel A: Targeted therapies in metastatic colorectal cancer: A systematic review and assessment of currently available data. Oncologist 19: 1156-1168, 2014.

3 Hurwitz H, Fehrenbacher L, Novotny W, Cartwright T, Hainsworth J, Heim W, Berlin J, Baron A, Griffing S, Holmgren E, Ferrara N, Fyfe G, Rogers B, Ross R and Kabbinavar F: Bevacizumab plus irinotecan, fluorouracil, and leucovorin for metastatic colorectal cancer. New Engl J Med 350: 2335-2342, 2004.

4 Van Cutsem E, Köhne C-H, Hitre E, Zaluski J, Chang Chien C-R, Makhson A, D'Haens G, Pintér T, Lim R, Bodoky G, Roh JK, Folprecht G, Ruff P, Stroh C, Tejpar S, Schlichting M, Nippgen J and Rougier P: Cetuximab and chemotherapy as initial treatment for metastatic colorectal cancer. New Engl J Med 360: 1408-1417, 2009.

5 Lee JJ and Chu E: Sequencing of angiangiogenic agents in the treatment of metastatic colorectal cancer. Clin Colorectal Cancer 13: 135-144, 2014.

6 Wilhelm SM, Dumas J, Adnane L, Lynch M, Carter CA, Schütz G, Thierauch KH and Zopf D: Regorafenib (BAY 73-4506): a new oral multikinase inhibitor of angiogenic, stromal and oncogenic receptor tyrosine kinases with potent preclinical antitumor activity. Int J Cancer 129: 245-255, 2011.

7 U.S. Food and Drug Administration: Drug Approval Package: Stivarga (regorafenib) tablets NDA \# 203085. 2012. https: //www.accessdata.fda.gov/drugsatfda_docs/nda/2012/203085 Orig1s000TOC.cfm (accessed July 16, 2017).

8 Grothey A, Van Cutsem E, Sobrero A, Siena S, Falcone A, Ychou M, Humblet Y, Bouché O, Mineur L, Barone C, Adenis A, Tabernero J, Yoshino T, Lenz HJ, Goldberg RM, Sargent DJ, Cihon F, Cupit L, Wagner A and Laurent D: Regorafenib monotherapy for previously treated metastatic colorectal cancer (CORRECT): an international, multicentre, randomised, placebo-controlled, phase 3 trial. Lancet 381: 303-312, 2013.

9 Li J, Qin S, Xu R, Yau TC, Ma B, Pan H, Xu J, Bai Y, Chi Y, Wang L, Yeh KH, Bi F, Cheng Y, Le AT, Lin JK, Liu T, Ma D, Kappeler C, Kalmus J and Kim TW: Regorafenib plus best supportive care versus placebo plus best supportive care in Asian patients with previously treated metastatic colorectal cancer (CONCUR): a randomised, double-blind, placebo-controlled, phase 3 trial. Lancet Oncol 16: 619-629, 2015.
10 Adenis A, de la Fouchardiere C, Paule B, Burtin P, Tougeron D, Wallet J, Dourthe LM, Etienne PL, Mineur L, Clisant S, Phelip JM, Kramar A and Andre T: Survival, safety, and prognostic factors for outcome with Regorafenib in patients with metastatic colorectal cancer refractory to standard therapies: results from a multicenter study (REBECCA) nested within a compassionate use program. BMC Cancer 16: 412, 2016.

11 Higgins JPT, Lasserson T, Chandler J, Tovey D, Churchill R. Methodological Expectations of Cochrane Intervention Reviews. Cochrane: London, 2016.

12 Sterne JA, Hernán MA, Reeves BC, Savović J, Berkman ND, Viswanathan M, Henry D, Altman DG, Ansari MT, Boutron I, Carpenter JR, Chan AW, Churchill R, Deeks JJ, Hróbjartsson A, Kirkham J, Jüni P, Loke YK, Pigott TD, Ramsay CR, Regidor D, Rothstein HR, Sandhu L, Santaguida PL, Schünemann HJ, Shea B, Shrier I, Tugwell P, Turner L, Valentine JC, Waddington $\mathrm{H}$, Waters E, Wells GA, Whiting PF and Higgins JP: ROBINSI: a tool for assessing risk of bias in non-randomised studies of interventions. BMJ 355: i4919, 2016.

13 Higgins JP, Thompson SG, Deeks JJ and Altman DG: Measuring inconsistency in meta-analyses. Br Med J 327: 557-560, 2003.

14 Neyeloff JL, Fuchs SC and Moreira LB: Meta-analyses and Forest plots using a Microsoft Excel spreadsheet: step-by-step guide focusing on descriptive data analysis. BMC Res Notes 5: 52, 2012.

15 Osawa H: Response to regorafenib at an initial dose of $120 \mathrm{mg}$ as salvage therapy for metastatic colorectal cancer. Mol Clin Oncol 6: 365-372, 2017.

16 Lam KO, Lee KC, Chiu J, Lee VH, Leung R, Choy TS and Yau T: The real-world use of regorafenib for metastatic colorectal cancer: multicentre analysis of treatment pattern and outcomes in Hong Kong. Postgrad Med J 93: 395-400, 2016.

17 Masuishi T, Taniguchi H, Hamauchi S, Komori A1, Kito Y, Narita Y, Tsushima T, Ishihara M, Todaka A, Tanaka T, Yokota T, Kadowaki S, Machida N, Ura T, Fukutomi A, Ando M, Onozawa Y, Tajika M, Yasui H, Muro K, Mori K and Yamazaki $\mathrm{K}$ : Regorafenib versus trifluridine/tipiracil for refractory metastatic colorectal cancer: A retrospective comparison. Clin Colorectal Cancer 16: e15-e22, 2016.

18 Calcagno F, Lenoble S, Lakkis Z, Nguyen T, Limat S, Borg C, Jary M, Kim S and Nerich V: Efficacy, safety and cost of regorafenib in patients with metastatic colorectal cancer in French clinical practice. Clin Med Insights Oncol 10: 59-66, 2016.

19 Zanwar S, Ostwal V, Gupta S, Sirohi B, Toshniwal A, Shetty N and Banavali S: Toxicity and early outcomes of regorafenib in multiply pre-treated metastatic colorectal adenocarcinomaexperience from a tertiary cancer centre in India. Ann Transl Med 4: 74, 2016.

20 Kim ST, Kim TW, Kim KP, Kim TY, Han SW, Lee JY, Lim SH, Lee MY, Kim H and Park YS: Regorafenib as salvage treatment in Korean patients with refractory metastatic colorectal cancer. Cancer Res Treat 47: 790-795, 2015.

21 Hirano G, Makiyama A, Makiyama C, Esaki T, Oda H, Uchino K, Komoda M, Tanaka R, Matsushita Y, Mitsugi K, Shibata Y, Kumagai H, Arita S, Ariyama H, Kusaba H, Akashi K and Baba E: Reduced dose of salvage-line regorafenib monotherapy for metastatic colorectal cancer in Japan. Anticancer Res 35: 371$377,2015$. 
22 Giampieri R, Prete MD, Prochilo T, Puzzoni M, Pusceddu V, Pani F, Maccaroni E, Mascia R, Baleani MG, Meletani T, Berardi, Lanzillo AM, Mariotti S, Zaniboni A, Cascinu S and Scartozzi M: Off-target effects and clinical outcome in metastatic colorectal cancer patients receiving regorafenib: The TRIBUTE analysis. Sci Rep 7: 45703, 2017.

23 Lim Y, Bang JI, Han SW, Paeng JC, Lee KH, Kim JH, Kang GH, Jeong SY, Park KJ and Kim TY: Total lesion glycolysis (TLG) as an imaging biomarker in metastatic colorectal cancer patients treated with regorafenib. Eur J Nucl Med Mol Imaging 44: 757-764, 2017.

24 Kakizawa N, Suzuki K, Fukui T, Takayama Y, Ichida K, Muto Y, Hasegawa F, Watanabe F, Kikugawa R, Tsujinaka S, Futsuhara K, Miyakura Y, Noda H and Rikiyama T: Clinical and molecular assessment of regorafenib monotherapy. Oncol Rep 37: 2506-2512, 2017.

25 Kopeckova K, Buchler T, Bortlicek Z, Hejduk K, Chloupkova R, Melichar B, Pokorna P, Tomasek J, Linke Z, Petruzelka L, Kiss I and Prausova J: Regorafenib in the real-life clinical practice: Data from the Czech Registry. Target Oncol 12: 89-95, 2017.

26 Sueda T, Sakai D, Kudo T, Sugiura T, Takahashi H, Haraguchi N, Nishimura J, Hata T, Hayashi T, Mizushima T, Doki Y, Mori $\mathrm{M}$ and Satoh T: Efficacy and safety of regorafenib or Tas-102 in patients with metastatic colorectal cancer refractory to standard therapies. Anticancer Res 36: 4299-4306, 2016.

27 Porta J, Paglino C, Imarisio I and Ferraris E: Sorafenib tosylate in advanced kidney cancer: past,present and future. Anticancer Drugs 20: 409-415, 2009.

28 Sirohi, B, Philip DS and Shrikhande SV: Regorafenib in gastrointestinal stromal tumors. Future Oncol 10: 1581-1587, 2014.
29 Rimassa L, Pressiani T, Personeni N and Santoro A: Regorafenib for the treatment of unresectable hepatocellular carcinoma. Expert Rev Anticancer Ther 17: 567-576, 2017.

30 Van Cutsem E, Ciardiello F, Seitz J-F, Hofheinz R, Verma U, Garcia-Carbonero R and Grothey A, Miriyala A, Kalmus J, Shapiro JA, Falcone A and Zaniboni A: LBA-05 Results from the large, open-label phase $3 \mathrm{~b}$ CONSIGN study of regorafenib in patients with previously treated metastatic colorectal cancer. Ann Oncol 26: iv118, 2015.

31 García-Alfonso P and Feliú J, García-Carbonero R, Grávalos C, Guillén-Ponce C, Sastre J, García-Foncillas J: Is regorafenib providing clinically meaningful benefits to pretreated patients with metastatic colorectal cancer? Clin Transl Oncol 18: 10721081, 2016

32 Loaiza-Bonilla A and Jensen CE, Shroff S, Furth E, BonillaReyes PA, Deik AF and Morrissette J: KDR mutation as a novel predictive biomarker of exceptional response to regorafenib in metastatic colorectal cancer. Cureus 8: e478, 2016.

33 Subbiah V, Rizwan Khawala M, Hong DS, Amini B, Yungfang J, Liu H, Johnson A, Schrock AB, Ali SM, Sun JX, Fabrizio D, Piha-Paul S and Fu S, Tsimberidou AM, Naing A, Janku F, Karp DD, Overman M, Eng C, Kopetz S, Meric-Bernstam F and Falchook GS: First-in-human trial of multikinase VEGF inhibitor regorafenib and anti-EGFR antibody cetuximab in advanced cancer patients. JCI Insight 2: e90380, 2017.

Received August 11, 2017

Revised September 5, 2017

Accepted September 7, 2017 